\title{
Direct comparison of the acute subjective, emotional, autonomic, and endocrine effects of MDMA, methylphenidate, and modafinil in healthy subjects
}

\author{
Patrick C. Dolder $^{1}$ - Felix Müller ${ }^{2}$ - Yasmin Schmid ${ }^{1} \cdot$ Stefan J. Borgwardt $^{2}$ • \\ Matthias E. Liechti ${ }^{1}$
}

Received: 21 February 2017 / Accepted: 9 May 2017 /Published online: 27 May 2017

(C) The Author(s) 2017. This article is an open access publication

\begin{abstract}
Rationale 3,4-Methylenedioxymethamphetamine (MDMA) is used recreationally and investigated as an adjunct to psychotherapy. Methylphenidate and modafinil are psychostimulants that are used to treat attention-deficit/hyperactivity disorder and narcolepsy, respectively, but they are also misused as cognitive enhancers. Little is known about differences in the acute effects of equally cardiostimulant doses of these stimulant-type substances compared directly within the same subjects.

Methods We investigated the acute autonomic, subjective, endocrine, and emotional effects of single doses of MDMA $(125 \mathrm{mg})$, methylphenidate $(60 \mathrm{mg})$, modafinil $(600 \mathrm{mg})$, and placebo in a double-blind, cross-over study in 24 healthy participants. Acute drug effects were tested using psychometric scales, the Facial Emotion Recognition Task (FERT), and the Sexual Arousal and Desire Inventory (SADI).

Results All active drugs produced comparable hemodynamic and adverse effects. MDMA produced greater increases in pupil dilation, subjective good drug effects, drug liking, happiness, trust, well-being, and alterations in consciousness than
\end{abstract}

The study was registered at ClinicalTrials.gov (NCT01951508).

Electronic supplementary material The online version of this article (doi:10.1007/s00213-017-4650-5) contains supplementary material, which is available to authorized users.

Matthias E. Liechti

matthias.liechti@usb.ch

1 Division of Clinical Pharmacology and Toxicology, Department of Biomedicine, Department of Clinical Research, University Hospital Basel and University of Basel, Schanzenstrasse 55,

CH-4056 Basel, Switzerland

2 Department of Psychiatry (UPK), University of Basel, Basel, Switzerland methylphenidate or modafinil. Only MDMA reduced subjective anxiety and impaired fear recognition and led to misclassifications of emotions as happy on the FERT. On the SADI, only MDMA produced sexual arousal-like effects. Only MDMA produced marked increases in cortisol, prolactin, and oxytocin. In contrast to MDMA, methylphenidate increased subjective anxiety, and methylphenidate and modafinil increased misclassifications of emotions as angry on the FERT. Modafinil had no significant subjective drug effects but significant sympathomimetic and adverse effects. Conclusions MDMA induced subjective, emotional, sexual, and endocrine effects that were clearly distinct from those of methylphenidate and modafinil at the doses used.

Keywords MDMA $\cdot$ Methylphenidate $\cdot$ Modafinil $\cdot$ Emotion recognition $\cdot$ Sexual arousal

\section{Introduction}

3,4-Methylenedioxymethamphetamine (MDMA, ecstasy) is used recreationally and investigated as an adjunct to psychotherapy for patients with posttraumatic stress disorder (Mithoefer et al. 2010; Oehen et al. 2013). Methylphenidate and modafinil are stimulants that are used to treat attentiondeficit/hyperactivity disorder and narcolepsy, respectively, but also misused as cognitive enhancers (Liakoni et al. 2015; Maier et al. 2015; Maier et al. 2013; Repantis et al. 2010). The neurotransmitter interaction profile of MDMA clearly differs from classic psychostimulants (Liechti 2015). MDMA releases serotonin and oxytocin (Francis et al. 2016; Hysek et al. 2012c; Kirkpatrick et al. 2014b; Simmler et al. 2013), in contrast to psychostimulant amphetamines (Liechti 2015; Simmler et al. 2013) and related substances, such as methylphenidate and modafinil, that enhance dopaminergic 
and noradrenergic neurotransmission without affecting serotonin or oxytocin (Hannestad et al. 2010; Madras et al. 2006; Qu et al. 2008; Schmeichel and Berridge 2013; Schmid et al. 2014; Simmler et al. 2014; Zolkowska et al. 2009). The main goal of the present study was to characterize and compare the effects of MDMA with the stimulant-type substances methylphenidate and modafinil at single relatively high doses matched for their cardiostimulant properties (comparable rate-pressure products; Hysek et al. 2014b; Jasinski 2000).

The acute effects of MDMA have been extensively studied in healthy subjects (Dumont and Verkes 2006; Vizeli and Liechti 2017) but only rarely compared directly with other orally administered stimulant substances (Hysek et al. 2014b; Parrott et al. 2011; Schmid et al. 2014; Tancer and Johanson 2003). MDMA induced greater "empathogenic" mood effects, including closeness to others, openness, trust, happiness, and wanting to be with others, compared with oral methylphenidate (Hysek et al. 2014a; Schmid et al. 2014). MDMA, but not methylphenidate, impaired the recognition of sad and fearful emotions on the Face Emotion Recognition Task (FERT) and increased biomarkers of serotonergic activity, including plasma concentrations of cortisol, prolactin, and oxytocin (Bedi et al. 2010; Hysek et al. 2014a; Kirkpatrick et al. 2014b; Kuypers et al. 2017; Schmid et al. 2014). In contrast, methylphenidate, but not MDMA, increased subjective concentration (Hysek et al. 2014a; Schmid et al. 2014) and sexual arousal that was elicited by explicit visual sexual stimuli (Schmid et al. 2015b). MDMA produced greater drug liking, elation, and good drug effects than amphetamine (Tancer and Johanson 2003), whereas other studies reported positive mood following methamphetamine but not MDMA administration (Parrott et al. 2011). However, these studies used only a few outcome measures and did not comprehensively evaluate emotional drug effects. MDMA may have unique empathogenic and prosocial effects that are distinct from classic stimulants (Bedi et al. 2010; Bershad et al. 2016; Hysek et al. 2014b; Kamilar-Britt and Bedi 2015; Schmid et al. 2014), but these differences need to be confirmed using blinded administration of MDMA and different stimulants within the same subjects. Therefore, the present cross-over study directly compared the subjective, emotional, autonomic, sexual, and endocrine effects of MDMA, methylphenidate, and modafinil. We expected MDMA to produce acute effects that are distinct from those of methylphenidate and modafinil. The a priori hypotheses defined in the study protocol were that MDMA, but not methylphenidate or modafinil, at the doses used, will produce prosocial and empathic feelings (closeness to others, openness, trust, want to be with other people) and elevate plasma levels of oxytocin (Hysek et al. 2014a; Hysek et al. 2014b; Schmid et al. 2014).

The acute effects of modafinil and methylphenidate are also different. Amphetamine and methylphenidate have greater subjective effects than modafinil (Franke et al. 2017; Jasinski 2000; Makris et al. 2007). In contrast, modafinil may have greater wakefulness-promoting effects than methylphenidate (Jasinski 2000; Repantis et al. 2010). In addition to comparisons with MDMA, the present study directly compared the effects of the neuroenhancers methylphenidate and modafinil in healthy subjects, complementing a previous study in stimulant users (Jasinski 2000).

\section{Materials and methods}

\section{Study design}

We used a double-blind, placebo-controlled, randomized, cross-over design with four experimental sessions (125 mg MDMA, $60 \mathrm{mg}$ methylphenidate, $600 \mathrm{mg}$ modafinil, and placebo) in 24 subjects. The order of the four experimental sessions was counterbalanced. The washout periods between sessions were at least 7 days. The study was conducted in accordance with the Declaration of Helsinki and approved by the Ethics Committee of Basel and the Swiss Agency for Therapeutic Products (Swissmedic). All of the subjects provided written consent before participating in the study, and they were paid for their participation. The study was registered at ClinicalTrials.gov (NCT01951508).

\section{Participants}

Twenty-four healthy subjects (12 men, 12 women), mean \pm SD age of $22.6 \pm 3.0$ years (range, $19-29$ years), were recruited from the University of Basel. The inclusion criteria were $18-45$ years old and body mass index of $18-27 \mathrm{~kg} / \mathrm{m}^{2}$. Subjects with a personal or first-degree-relative history of psychiatric disorders or chronic or acute physical illness were excluded. Additional exclusion criteria were tobacco smoking ( $>10$ cigarettes/day) and a lifetime history of using illicit drugs more than five times, with the exception of occasional cannabis use in the past. In contrast to similar studies in other laboratories, the majority of the participants had never used MDMA or other illicit drugs with the exception of cannabis (Kirkpatrick et al. 2014a; Kuypers et al. 2017). Four participants had used MDMA (one-three times), two had used cocaine on a single occasion, one had used LSD once, one psilocybin once, and three methylphenidate (once or twice). Four had never used cannabis, 11 had used cannabis 1-20 times, and 9 participants had used cannabis $>20$ times ranging from once/month to 4 times per week. Subjects who used any illicit drugs, including cannabis, within the past 2 months or during the study period were excluded. We performed drug tests at screening and before each test session using TRIAGE 8 (Biosite, San Diego, CA, USA). All female subjects used oral contraceptives and were investigated during the follicular 
phase of their menstrual cycle (day 2-14 after the start of the menstruation) to account for cyclic changes in reactivity, which has been demonstrated for amphetamines (White et al. 2002).

\section{Study procedures}

The study included a prescreening telephone interview, a screening visit, four experimental sessions (test days), and an end-of-study visit. The experimental sessions began at 8:45 AM. An indwelling intravenous catheter was placed in an antecubital vein for blood sampling, and baseline measurements were performed. MDMA, methylphenidate, modafinil, or placebo was administered at 9:45 AM. Autonomic and subjective effects were assessed repeatedly throughout the session. Blood was collected to determine endocrine effects and substance concentrations. A functional magnetic resonance imaging (fMRI) scan was performed at 11:15 AM12:15 PM during the expected drug peak effects (Hysek et al. 2014b; Schmid et al. 2014; Wong et al. 1998). The fMRI findings will be published elsewhere. Face emotion recognition was assessed at 12:15 PM. A standardized small lunch was served at 1:15 PM, and the subjects were sent home at 3:45 PM.

\section{Study drugs}

\pm MDMA hydrochloride (Lipomed AG, Arlesheim, Switzerland) was prepared as gelatin capsules with mannitol as the filler. Identical placebo (only mannitol) capsules were prepared. MDMA was administered in a single absolute dose of $125 \mathrm{mg}$ corresponding to a relatively high dose of (mean $\pm \mathrm{SD}$ ) $1.9 \pm 0.3 \mathrm{mg} / \mathrm{kg}$ body weight. This dose of MDMA is in the high range of the doses typically used in clinical research (Kirkpatrick et al. 2015; Kirkpatrick et al. 2014a; Kuypers et al. 2017) but also used in clinical studies in patients with PTSD (Mithoefer et al. 2010; Oehen et al. 2013) and is within the dose range that is used recreationally (Brunt et al. 2012). Immediate-release methylphenidate tablets (10 mg, Ritalin, Novartis AG, Rotkreuz, Switzerland) were encapsulated within opaque gelatin capsules, and identical placebo capsules were prepared. The therapeutic starting dose of methylphenidate is $10 \mathrm{mg}$ and average therapeutic doses are $20-30 \mathrm{mg} /$ day. Methylphenidate was administered in a single relatively high dose of $60 \mathrm{mg}$ (Korostenskaja et al. 2008; Martin et al. 1971). The subjective and cardiostimulant effects of this dose have previously been assessed on the same tests (Hysek et al. 2014b) and have also been statistically compared with a lower dose of $40 \mathrm{mg}$ (Schmid et al. 2014). The doses of MDMA and methylphenidate used were expected to be equivalent regarding their cardiovascular stimulant effects (Hysek et al. 2014b). Modafinil tablets (100 mg, Teva Pharma AG, Basel, Switzerland) were encapsulated within opaque gelatin capsules, and identical placebo capsules were prepared. The therapeutic starting dose of modafinil is $100 \mathrm{mg}$ and common doses are $400 \mathrm{mg} /$ day. Modafinil was administered in a single high dose of $600 \mathrm{mg}$. The goal was to use high single doses of all substances with comparable cardiostimulant effects (Hysek et al. 2014b; Jasinski 2000) and to maximize the subjective drug effects.

\section{Measures}

Autonomic effects Blood pressure, heart rate, and tympanic body temperature were repeatedly measured $1 \mathrm{~h}$ before and 0 , $0.3,0.6,1,1.25,1.5,2.5,3,4,5$, and $6 \mathrm{~h}$ after drug administration as previously described in detail (Hysek et al. 2010). The peak rate-pressure product (systolic blood pressure $\times$ heart rate) was the main autonomic outcome measure reflecting the maximal total hemodynamic response to a substance and expected to be comparable across substances at the doses used (Hysek et al. 2014b; Jasinski 2000).

Subjective effects Subjective effects were assessed repeatedly using visual analog scales (VASs) $1 \mathrm{~h}$ before and $0,0.3,0.6,1$, $1.25,1.5,2.5,3,4,5$, and $6 \mathrm{~h}$ after drug administration. The VASs included "any drug effect," "good drug effect," "bad drug effect," "drug liking," "happy," "concentration," "open," "trust," "feeling close to others," "I want to be with other people," and "I want to hug someone" (Hysek et al. 2014a). The VASs were presented as $100-\mathrm{mm}$ horizontal lines $(0$ $100 \%)$, marked from "not at all" on the left to "extremely" on the right. The 60-item Adjective Mood Rating Scale (AMRS; (Janke and Debus 1978)) and State-Trait Anxiety Inventory (STAI; (Spielberger et al. 1970)) were administered $1 \mathrm{~h}$ before and $1.25,2.5$, and $5 \mathrm{~h}$ after drug administration. The German version of the 49-item Addiction Research Center Inventory (ARCI; (Bopp et al. 2005; Martin et al. 1971)) was administered $1 \mathrm{~h}$ before and $1.25 \mathrm{~h}$ after drug administration. The 5-Dimensions of Altered States of Consciousness (5D-ASC) scale (Dittrich 1998; Studerus et al. 2010) was administered $5 \mathrm{~h}$ after drug administration to retrospectively rate the effects of the drugs.

Endocrine effects The plasma levels of prolactin, cortisol, oxytocin, and vasopressin were measured at baseline and 1.5 and $2.5 \mathrm{~h}$ after drug administration and analyzed as described previously (Hysek et al. 2012b; Neumann et al. 2013).

\section{Facial emotion recognition task}

We used the FERT, which is sensitive to the effects of MDMA (Bedi et al. 2010; Hysek et al. 2014b; Kirkpatrick et al. 2014b; Schmid et al. 2014) and methylphenidate (Hysek et al. 2014b; Schmid et al. 2014). The task included 10 neutral faces and 160 faces that expressed one of four basic emotions (i.e., 
happiness, sadness, anger, and fear), with pictures morphed between $0 \%$ (neutral) and $100 \%$ in $10 \%$ steps. Two female and two male pictures were used for each of the four emotions. The stimuli were presented in random order for $500 \mathrm{~ms}$ and then were replaced by the rating screen where participants had to indicate the correct emotion. The main outcome measure was accuracy (proportion correct). Additionally, we analyzed whether incorrectly identified emotional expressions were misclassified as neutral or other emotions (Bedi et al. 2010; Schmid et al. 2014). The FERT was performed $2.5 \mathrm{~h}$ after drug administration.

\section{Sexual arousal and desire Inventory}

The SADI is a self-report scale that includes 54 items (adjectives or short sentences) and measures subjective sexual arousal and desire (Persson et al. 2016; Toledano and Pfaus 2006). Each item is rated from 0 ("does not describe it at all") to 5 ("describes it perfectly"). The questionnaire includes four overlapping factors: "Evaluative," "Physiological," "Negative/Aversive," and "Motivational." The "Evaluative" scale consists of 27 items that describe cognitive and emotional aspects (i.e., tempted, passionate, seductive, attractive). The "Physiological" scale consists of 17 items that describe autonomic reactions to sexual arousal (i.e., sensitive to touch, stimulated, excited, heart beats faster). The "Negative/Aversive" scale consists of 17 items that describe aspects that are opposite to sexual arousal (i.e., anxious, displeasure, repulsion, angry). The "Motivational" scale consists of 10 items that are related to the motivation to engage in sexual activity (i.e., driven, urge to satisfy, horny, impatient). The SADI was administered $1 \mathrm{~h}$ before and $3 \mathrm{~h}$ after drug administration.

\section{Substance plasma concentrations}

The plasma levels of methylphenidate, modafinil, MDMA, and the MDMA metabolites 3,4-methylenedioxyamphetamine (MDA) and 4-hydroxy-3-methoxymethamphetamine (HMMA) were determined $1 \mathrm{~h}$ before and 1, 1.5, 2.5, 3, 4, and $6 \mathrm{~h}$ after substance administration using liquid chromatography-mass spectrometry/mass spectrometry as previously described (Hysek et al. 2012a; Hysek et al. 2014b). The maximal plasma concentration $\left(C_{\max }\right)$ and time to $C_{\max }\left(T_{\max }\right)$ were obtained directly from the observed concentration-time curves.

\section{Adverse effects}

Adverse effects were assessed $1 \mathrm{~h}$ before and $6 \mathrm{~h}$ (acute) and $24 \mathrm{~h}$ (sub-acute) after drug administration using the 66-item List of Complaints (Zerssen 1976). The scale yields a total adverse effects score and reliably measures physical and general discomfort.

\section{Statistical analyses}

Repeated measures are expressed as peak effects or peak changes from baseline $\left(E_{\max }\right)$. The data were analyzed using repeated-measures analysis of variance (ANOVA), with drug as the within-subjects factor, followed by Tukey post hoc comparisons based on significant main effects. Some of the VASs data were not normally distributed and were therefore analyzed using Friedman ANOVAs with drug as the withinsubject factor, followed by Wilcoxon matched pairs tests. The criterion for significance was $p<0.05$. The criterion was adjusted for the multiple comparisons within the VAS and the AMRS using the Bonferroni method.

\section{Results}

All 24 participants completed all sessions of the study. Autonomic, subjective, and endocrine peak effects and statistics are shown in Table 1 and Supplementary Table S1.

\section{Autonomic effects}

Drug effects on vital signs over time are shown in Fig. 1, and peak effects are shown in Table 1. All active substances produced comparable and significant increases in body temperature and similar hemodynamic stimulation, considering the similar increase in the rate-pressure products compared with placebo. MDMA markedly and significantly increased pupil size in the dark and after a light stimulus and decreased the constriction amplitude. Methylphenidate and modafinil produced only very small but significant increases in pupil size in the dark. MDMA produced significantly greater alterations in pupil function than methylphenidate and modafinil, including markedly greater pupil size in the dark and significantly lower responses to a light stimulus (Supplementary Fig. S1, Table 1).

\section{Subjective effects}

Subjective drug effects over time are shown in Fig. 2 and Fig. 3, and peak responses are shown in Table 1 and Supplementary Table S1. On the VASs (Fig. 2), MDMA increased ratings for any drug effect, good drug effect, drug liking, happiness, open, trust, feeling close to others, I want to be with other people, and I want to hug someone compared with placebo. Methylphenidate produced significant increases in any drug effect, good drug effect, and drug liking but only very small increases in ratings of open, and feeling close to others compared with placebo. Modafinil produced no significant subjective effects compared with placebo. MDMA increased ratings for any drug effect, good drug effect, drug liking, happy, trust, feeling close to others, and want to be with other people more than methylphenidate or modafinil. On the AMRS (Fig. 3), MDMA increased 
Table 1 Comparison of the acute effects of MDMA, methylphenidate, modafinil, and placebo $(N=24)$

\begin{tabular}{|c|c|c|c|c|c|c|c|}
\hline & & $\begin{array}{l}\text { Placebo } \\
(\text { mean } \pm \text { SEM })\end{array}$ & $\begin{array}{l}\text { MDMA } \\
(\text { mean } \pm \text { SEM })\end{array}$ & $\begin{array}{l}\text { Methylphenidate } \\
\text { (mean } \pm \text { SEM) }\end{array}$ & $\begin{array}{l}\text { Modafinil } \\
(\text { mean } \pm \text { SEM })\end{array}$ & $F 3.69$ & $p=$ \\
\hline \multicolumn{8}{|l|}{ Autonomic effects } \\
\hline Systolic blood pressure (mm Hg) & $E_{\max }$ & $135 \pm 3.0$ & $152 \pm 3.2 * * *$ & $145 \pm 3.1 * * * \#$ & $143 \pm 3.4 * * \# \#$ & 20.41 & $<0.001$ \\
\hline Diastolic blood pressure (mm Hg) & $E_{\max }$ & $78.8 \pm 1.6$ & $88.1 \pm 1.8^{* * *}$ & $84.0 \pm 1.8 * * \#$ & $85.7 \pm 2.0 * * *$ & 13.24 & $<0.001$ \\
\hline Heart rate (beats/min) & $E_{\max }$ & $73.1 \pm 2.5$ & $90.3 \pm 3.0 * * *$ & $91.6 \pm 3.6 * * *$ & $87.9 \pm 3.5^{* * *}$ & 23.82 & $<0.001$ \\
\hline Rate pressure product (beats $\cdot \mathrm{mmHg} / \mathrm{min}$ ) & $E_{\max }$ & $9603 \pm 383$ & $13,377 \pm 536 * * *$ & $12,985 \pm 625 * * *$ & $12,273 \pm 667 * * *$ & 26.15 & $<0.001$ \\
\hline Body temperature $\left({ }^{\circ} \mathrm{C}\right)$ & $E_{\max }$ & $37.3 \pm 0.1$ & $37.6 \pm 0.1^{* *}$ & $37.6 \pm 0.1 * *$ & $37.9 \pm 0.1 * * *$ & 12.55 & $<0.001$ \\
\hline Pupil size (mm) & $E_{\max }$ & $6.5 \pm 0.1$ & $7.4 \pm 0.1 * * *$ & $6.7 \pm 0.1 * * \# \#$ & $6.7 \pm 0.2 * \# \# \#$ & 76.11 & $<0.001$ \\
\hline Pupil size after light stimulus (mm) & $E_{\max }$ & $4.7 \pm 0.1$ & $6.4 \pm 0.2 * * *$ & $4.8 \pm 0.1 \# \# \#$ & $4.8 \pm 0.1 \# \# \#$ & 148.78 & $<0.001$ \\
\hline Constriction amplitude (mm) & $E_{\min }$ & $1.8 \pm 0.1$ & $0.86 \pm 0.10^{* * *}$ & $1.8 \pm 0.1 \# \# \#$ & $1.7 \pm 0.1 \# \# \#$ & 34.47 & $<0.001$ \\
\hline \multicolumn{8}{|l|}{ Subjective effects } \\
\hline \multicolumn{8}{|l|}{ Visual Analog Scale (VAS, \%max) } \\
\hline Any drug effect & $\Delta \mathrm{E}_{\max }$ & $10.0 \pm 2.4$ & $75.3 \pm 5.1 * * *$ & $32.8 \pm 6.8 * \# \# \#$ & $23.7 \pm 5.2 \# \# \#$ & 45.51 & $<0.001$ \\
\hline Good drug effect & $\Delta \mathrm{E}_{\max }$ & $7.5 \pm 2.5$ & $73.2 \pm 5.3 * * *$ & $35.5 \pm 7.7 * * \# \# \#$ & $23.9 \pm 5.4 \# \# \#$ & 45.68 & $<0.001$ \\
\hline Bad drug effect & $\Delta \mathrm{E}_{\max }$ & $4.2 \pm 3.3$ & $12.7 \pm 3.5$ & $11.5 \pm 4.5$ & $10.3 \pm 4.9$ & 10.49 & NS \\
\hline Drug liking & $\Delta \mathrm{E}_{\max }$ & $9.4 \pm 3.0$ & $75.5 \pm 5.5^{* * *}$ & $36.3 \pm 8.2 * \# \# \#$ & $24.8 \pm 5.4 \# \# \#$ & 40.9 & $<0.001$ \\
\hline Happy & $\Delta \mathrm{E}_{\max }$ & $2.7 \pm 1.2$ & $31.0 \pm 3.6^{* * *}$ & $10.8 \pm 3.6 \# \#$ & $8.1 \pm 2.4 \# \# \#$ & 41.06 & $<0.001$ \\
\hline Concentration & $\Delta \mathrm{E}_{\max }$ & $-6.5 \pm 1.5$ & $-29.3 \pm 3.4$ & $-11.6 \pm 3.6$ & $-13.3 \pm 3.6$ & 9.56 & NS \\
\hline Open & $\Delta \mathrm{E}_{\max }$ & $2.4 \pm 1.0$ & $19.6 \pm 3.7 * *$ & $11.2 \pm 3.5^{*}$ & $9.5 \pm 2.9$ & 20.08 & $<0.01$ \\
\hline Trust & $\Delta \mathrm{E}_{\max }$ & $1.5 \pm 0.9$ & $24.5 \pm 4.1 * *$ & $8.0 \pm 3.0 \# \#$ & $8.6 \pm 3.7 \#$ & 24.85 & $<0.001$ \\
\hline Feeling close to others & $\Delta \mathrm{E}_{\max }$ & $1.1 \pm 0.8$ & $18.5 \pm 3.8^{* *}$ & $9.7 \pm 2.6^{* \#}$ & $5.7 \pm 2.1 \#$ & 24.79 & $<0.001$ \\
\hline I want to be with other people & $\Delta \mathrm{E}_{\max }$ & $3.1 \pm 1.9$ & $21.0 \pm 4.3 * * *$ & $10.1 \pm 3.5 \#$ & $9.9 \pm 3.8 \#$ & 18.46 & $<0.01$ \\
\hline I want to hug someone & $\Delta \mathrm{E}_{\max }$ & $0.6 \pm 0.6$ & $15.1 \pm 3.6^{*}$ & $7.0 \pm 3.3$ & $3.3 \pm 2.3 \#$ & 23.13 & $<0.001$ \\
\hline \multicolumn{8}{|c|}{ Adjective Mood Rating Scale (AMRS score) } \\
\hline Well-being & $\Delta \mathrm{E}_{\max }$ & $0.04 \pm 0.37$ & $5.8 \pm 1.0 * * *$ & $2.5 \pm 0.7 \#$ & $1.3 \pm 0.7 \# \#$ & 14.52 & $<0.001$ \\
\hline Emotional excitation & $\Delta \mathrm{E}_{\max }$ & $-0.13 \pm 0.56$ & $3.0 \pm 0.9 *$ & $2.6 \pm 0.8$ & $1.2 \pm 0.7$ & 4.91 & $<0.05$ \\
\hline Activity & $\Delta \mathrm{E}_{\max }$ & $0.79 \pm 0.45$ & $2.0 \pm 0.6$ & $2.5 \pm 0.5$ & $0.50 \pm 0.4$ & 3.23 & NS \\
\hline Extroversion & $\Delta \mathrm{E}_{\max }$ & $0.0 \pm 0.4$ & $2.3 \pm 0.6 * *$ & $1.3 \pm 0.5$ & $1.36 \pm 0.5$ & 5.25 & $<0.05$ \\
\hline Introversion & $\Delta \mathrm{E}_{\max }$ & $0.50 \pm 0.29$ & $2.4 \pm 0.5^{*}$ & $1.3 \pm 0.4$ & $0.9 \pm 0.4$ & 4.36 & $<0.05$ \\
\hline Concentration & $\Delta \mathrm{E}_{\max }$ & $0.3 \pm 0.32$ & $0.46 \pm 0.46$ & $1.13 \pm 0.42$ & $-0.33 \pm 0.25$ & 3.05 & NS \\
\hline \multicolumn{8}{|c|}{ State-Trait Anxiety Inventory (state anxiety score) } \\
\hline & $E_{\max }$ & $36.6 \pm 1.0$ & $37.6 \pm 1.4$ & $42.0 \pm 1.8^{*}$ & $39.5 \pm 1.6$ & 3.25 & $<0.05$ \\
\hline & $E_{\min }$ & $32.8 \pm 0.9$ & $29.0 \pm 1 * * *$ & $34.5 \pm 1.0 \# \# \#$ & $32.5 \pm 1.2 \#$ & 6.58 & $<0.001$ \\
\hline \multicolumn{8}{|l|}{ Sexual Arousal and Desire Inventory } \\
\hline Evaluative & & $1.4 \pm 1.3$ & $19.5 \pm 4.3 * * *$ & $6.5 \pm 3.4 \#$ & $8.4 \pm 3.6 \#$ & 6.98 & $<0.001$ \\
\hline Negative/Aversive & & $0.04 \pm 1.3$ & $-0.09 \pm 1.5$ & $0.3 \pm 1.4$ & $4.9 \pm 2.6$ & 1.88 & NS \\
\hline Physiological & & $1.6 \pm 0.9$ & $13.2 \pm 2.4 * * *$ & $6.6 \pm 2.4 \#$ & $5.0 \pm 2.2 \# \#$ & 8.03 & $<0.001$ \\
\hline Motivational & & $0.4 \pm 0.6$ & $4.8 \pm 1.5^{*}$ & $1.1 \pm 1.2$ & $2.5 \pm 1.4$ & 3.22 & $<0.05$ \\
\hline \multicolumn{8}{|l|}{ Hormones } \\
\hline Cortisol (nmol/L) & $E_{\max }$ & $630 \pm 53.5$ & $942 \pm 41.5 * * *$ & $648 \pm 37.7 * * \# \#$ & $653 \pm 40.5 \# \# \#$ & 35.55 & $<0.001$ \\
\hline Prolactin (mU/L) & $E_{\max }$ & $334 \pm 32.7$ & $1086 \pm 143 * * *$ & $295 \pm 30.9 \# \# \#$ & $288 \pm 24.0$ \#\# & 30.46 & $<0.001$ \\
\hline Oxytocin (pg/mL) & $E_{\max }$ & $5.0 \pm 1.5$ & $58.7 \pm 7.9 * * *$ & $6.3 \pm 1.3 \# \# \#$ & $4.29 \pm 0.87 \# \# \#$ & 44.90 & $<0.001$ \\
\hline Vasopressin $(\mathrm{pg} / \mathrm{mL})$ & $E_{\max }$ & $4.1 \pm 0.3$ & $4.4 \pm 0.5$ & $4.23 \pm 0.67$ & $3.44 \pm 0.27$ & 2.15 & NS \\
\hline
\end{tabular}

VAS and AMRS $P$ values were Bonferroni adjusted values considering the multiple subscales used (11 and 6 for the VAS and AMRS, respectively) $N S$ not significant, Emax maximal effect, $\Delta E$ max maximal difference from baseline

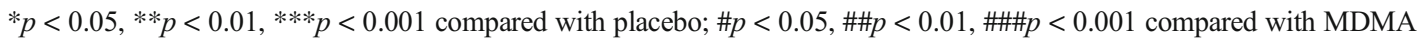



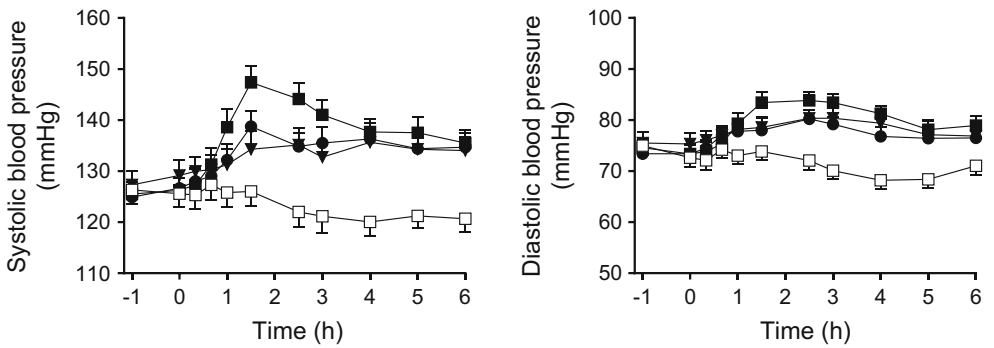

- MDMA

- Methylphenidate

$\checkmark$ Modafinil

$\square-$ Placebo
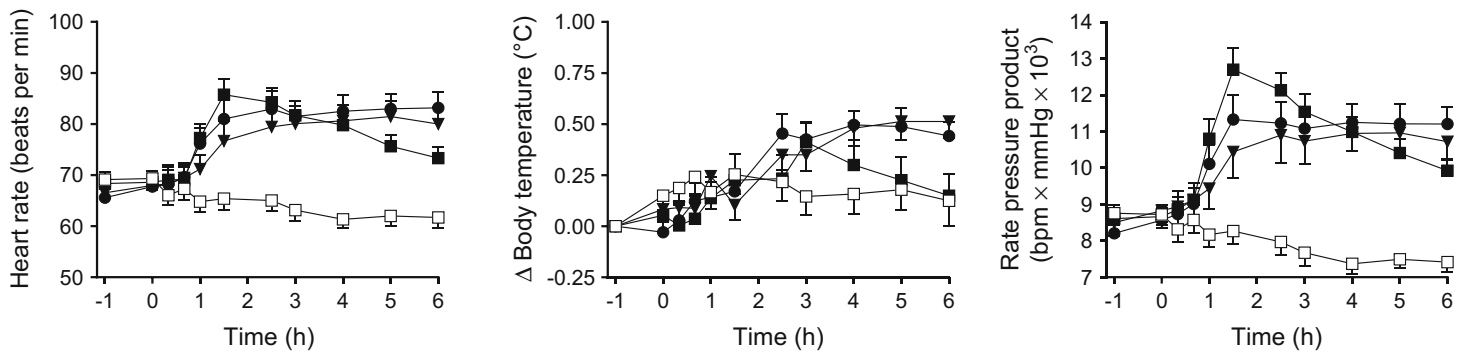

Fig. 1 Autonomic responses to MDMA, methylphenidate, modafinil, and placebo. All active treatments increased systolic and diastolic blood pressure, heart rate, and body temperature. MDMA produced slightly

However, the overall hemodynamic response, expressed as the rate pressure product, similarly increased after all active treatments compared with placebo. The data are expressed as the mean \pm SEM in higher increases in blood pressure than methylphenidate and modafinil.

24 subjects. The substances were administered at $t=0$
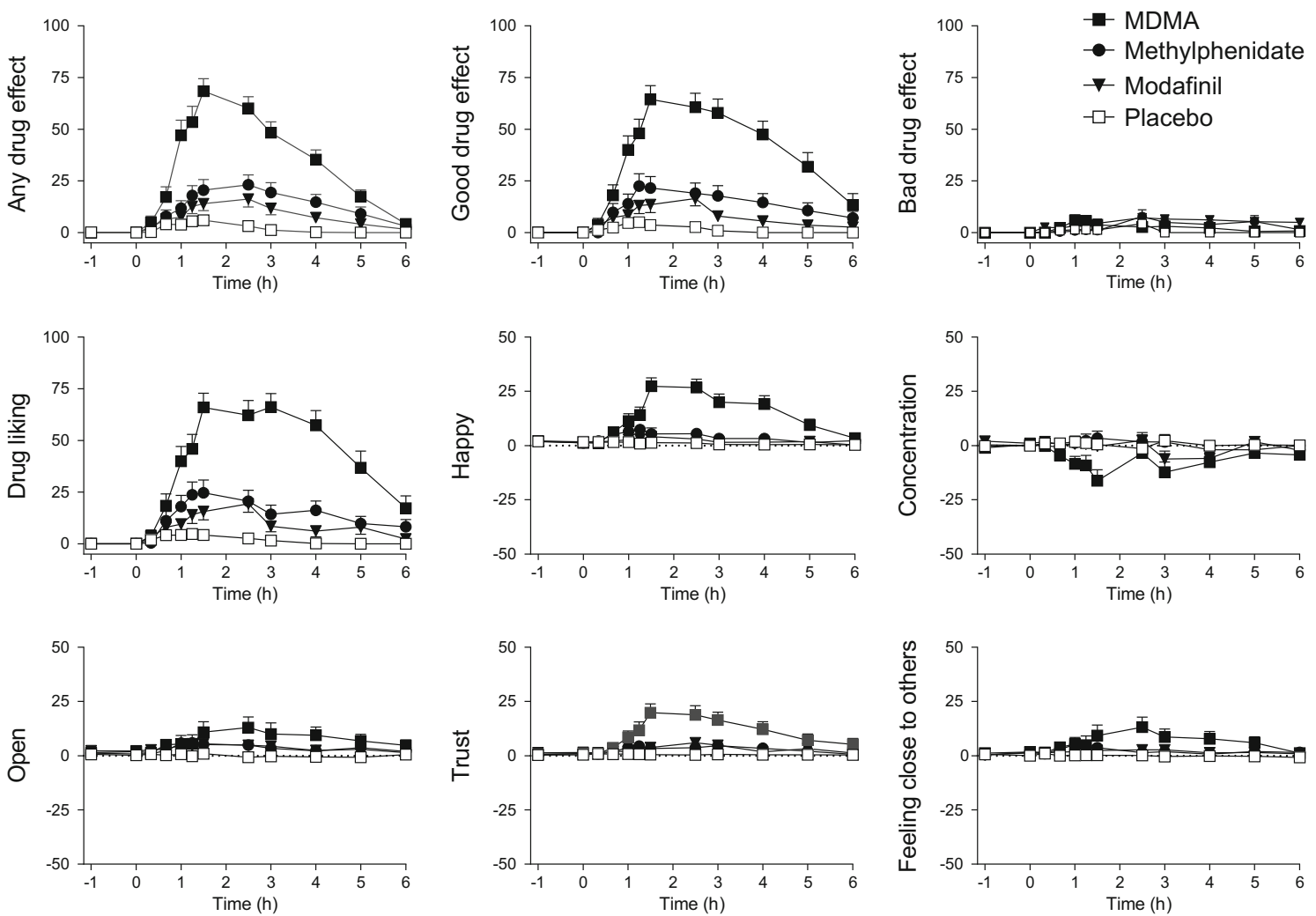

Fig. 2 Subjective effects of MDMA, methylphenidate, modafinil, and placebo on the VASs. MDMA produced greater subjective effect ratings on most VASs compared with methylphenidate and modafinil. MDMA produced greater any drug effects, good drug effects, drug liking, happiness, trust, and feeling close to others than methylphenidate and modafinil. None of the substances produced significant bad drug effects compared with placebo. Modafinil did not produce any significant subjective effects compared with placebo. The data are expressed as the mean \pm SEM in 24 subjects. The substances were administered at $t=0$ 

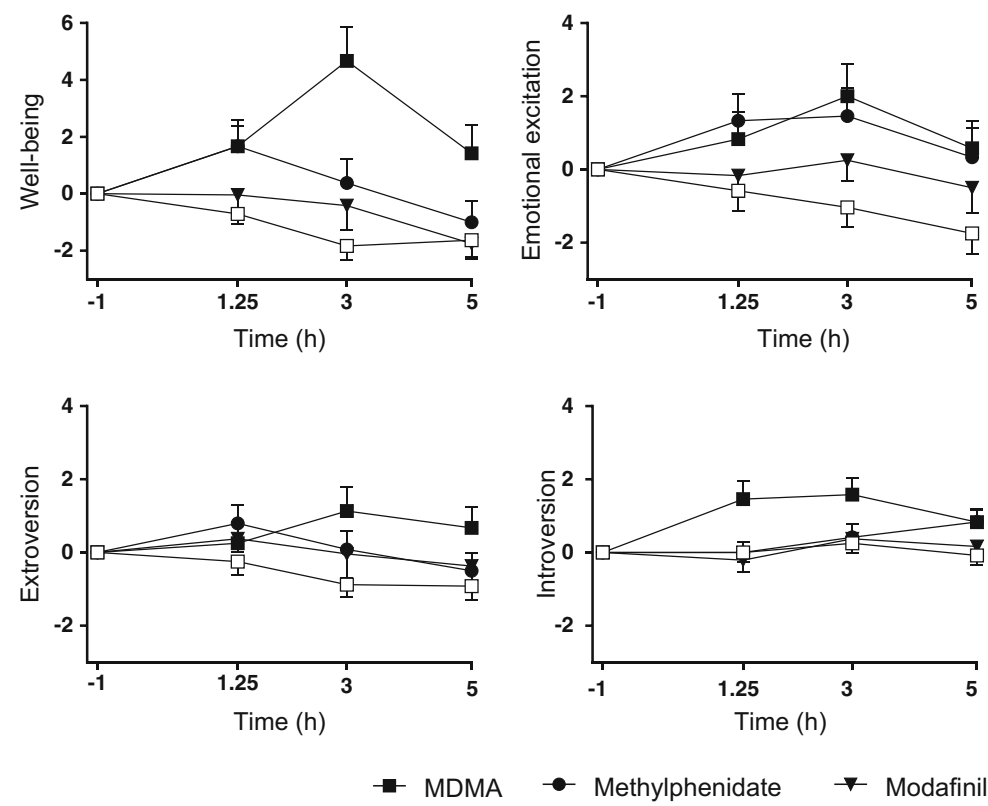

$\bullet$ Methylphenidate

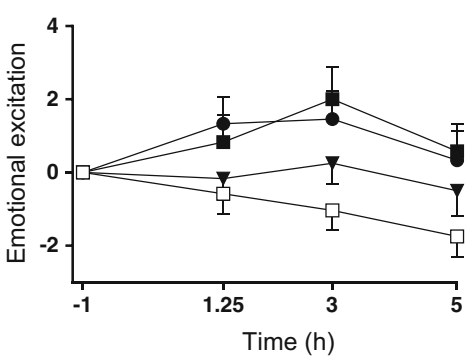

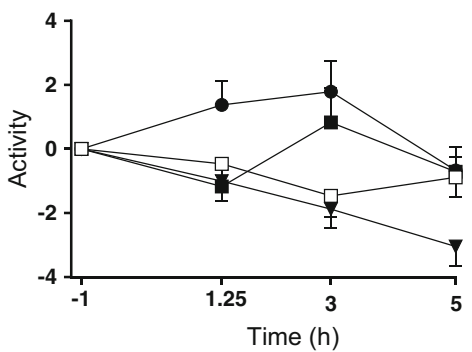

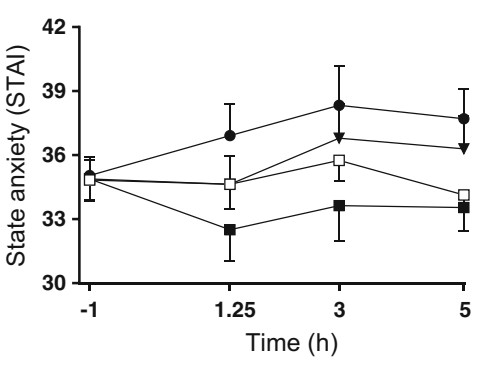

$\neg$ Placebo
Fig. 3 On the AMRS, MDMA significantly increased ratings of wellbeing, emotional excitation, extroversion, and introversion. Methylphenidate and modafinil produced no effects on any of the

well-being, emotional excitation, extraversion, and introversion compared with placebo. Methylphenidate and modafinil had no effects on the AMRS. MDMA increased well-being more than methylphenidate or modafinil. On the STAI (Fig. 3), MDMA reduced state anxiety, methylphenidate increased anxiety, and modafinil had no effect. On the ARCI (Supplementary Table S1), MDMA increased amphetamine-group, morphine, and pentobarbital-chlorpromazine-alcohol group ratings compared with placebo. Methylphenidate increased amphetamine and benzedrine group ratings compared with placebo. Modafinil had no significant effects on the ARCI. MDMA increased morphine and pentobarbital-chlorpromazine-alcohol group ratings significantly more than methylphenidate and modafinil. On the 5D-ASC scale (Supplementary Table S1), MDMA produced effects on oceanic boundlessness and anxious ego dissolution. Methylphenidate and modafinil had no effects on any of the 5D-ASC scales.

\section{Endocrine effects}

MDMA increased plasma concentrations of cortisol, prolactin, and oxytocin compared with placebo and all of the other active treatments (Fig. 4, Table 1). Methylphenidate produced a slight increase in cortisol concentrations, and modafinil had no effect. None of the active treatments increased vasopressin concentrations.

\section{Facial emotion recognition}

The effects of MDMA, methylphenidate, and modafinil on the FERT are shown in Fig. 5. Complete datasets were
AMRS scales. On the STAI, MDMA decreased state anxiety, and methylphenidate increased state anxiety. The data are expressed as the mean \pm SEM in 24 subjects. The substances were administered at $t=0$

unavailable for two subjects because of technical reasons. The ANOVA revealed a significant main effect of drug on the decoding accuracy of fearful faces $\left(F_{3,63}=7.38\right.$ $p<0.001)$. The post hoc tests showed that MDMA significantly impaired the recognition of fearful faces compared with placebo $(p<0.001)$, methylphenidate $(p<0.01)$, and modafinil $(p<0.05)$. There was a significant main effect of drug on misclassification of emotions as happy $\left(F_{3,63}=3.35 p<0.05\right)$. MDMA significantly increased the misclassification of emotions as happy compared with placebo $(p<0.05)$. In contrast, methylphenidate $(p<0.05)$ and modafinil $(p<0.05)$ increased misclassifications of emotions as angry (main effect of drug: $\left.F_{3,63}=3.38 p<0.05\right)$. However, methylphenidate and modafinil did not alter emotion recognition accuracy for any of the emotions.

\section{Sexual arousal and desire}

Data from one subject were missing. Only MDMA increased scores on the "Evaluative" ( $p<0.001)$, "Physiological" $(p<0.001)$, and "Motivational" $(p<0.05)$ scales compared with placebo, but it did not influence scores on the "Negative/ Aversive" scale (Table 1). MDMA produced significantly higher ratings on the "Physiological" factor items "tingly all over," "sensitive to touch," "enthusiastic," "warm all over," "flushed," "heart beats faster," and "seductive" compared with placebo. MDMA produced significantly higher ratings on the "Evaluative" factor items "enthusiastic," "warm all over," "passionate," "sensual," "pleasure," "heart beats faster," "happy," "powerful," and "forget about all else" 
Fig. 4 Endocrine effects of MDMA, methylphenidate, modafinil, and placebo. MDMA increased levels of cortisol, prolactin, and oxytocin compared with placebo. Methylphenidate produced a weak but significant increase in cortisol compared with placebo. Modafinil had no endocrine effects. The data are expressed as the mean \pm SEM in 24 subjects. The substances were administered at $t=0$
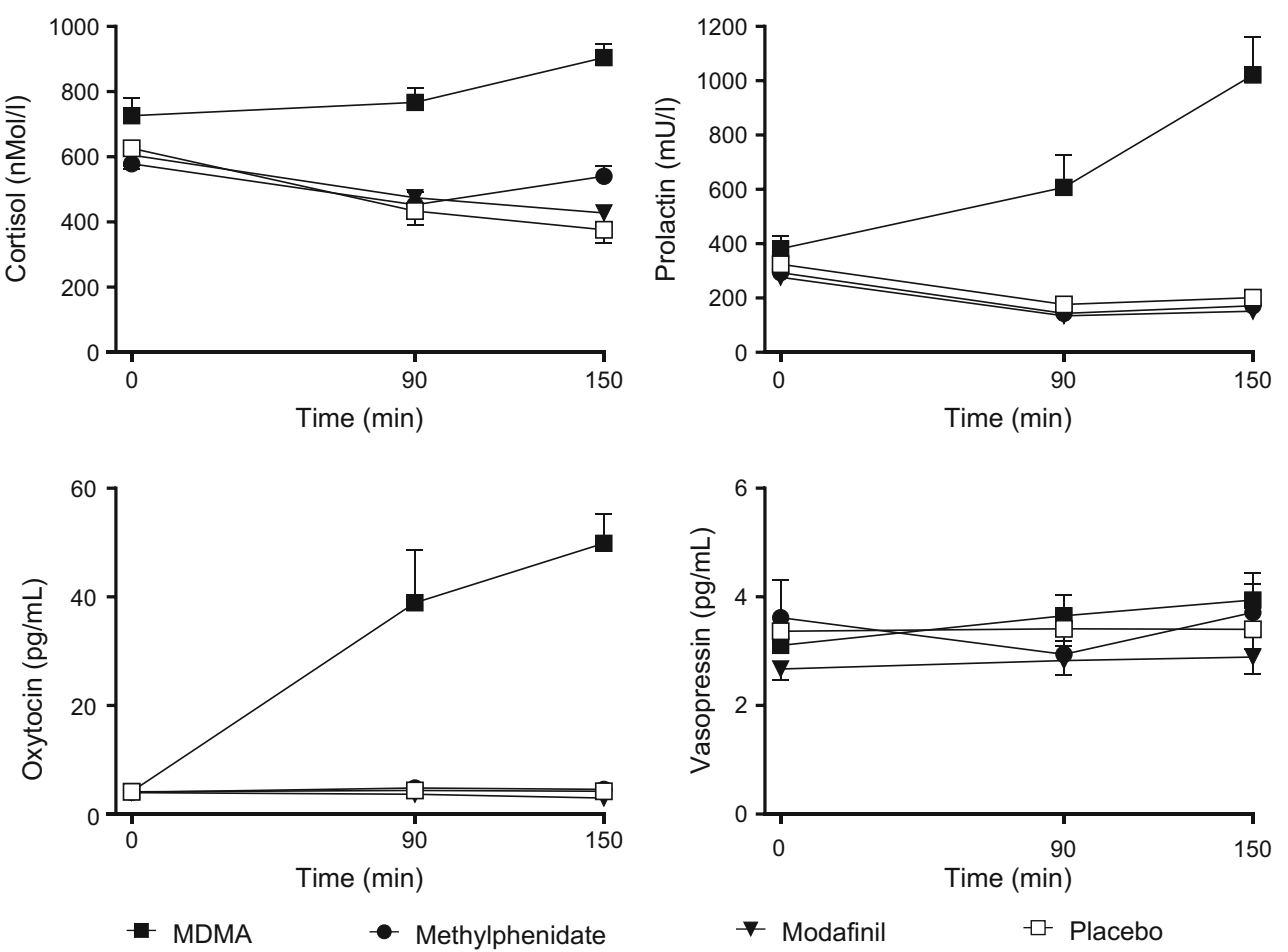

$\checkmark$ Modafinil $\quad \square-$ Placebo compared with placebo MDMA produced significantly higher ratings on the "Motivational" factor item "anticipatory" compared with placebo.

\section{Substance plasma concentrations}

The concentration-time curves for methylphenidate, modafinil, MDMA, MDA, and HMMA are shown in Supplementary Fig. S2. The $C_{\max }$ values for MDMA, MDA, and HMMA were $192 \pm 8.7,9.1 \pm 0.4$, and $69.1 \pm 10.0 \mathrm{ng} / \mathrm{ml}$, respectively. The $T_{\max }$ values were $3.7 \pm 0.3,5.7 \pm 0.2$, and $4.2 \pm 0.3 \mathrm{~h}$, respectively. The $C_{\max }$ values for methylphenidate and modafinil were $27.0 \pm 2.1$ and $13.2 \pm 0.5 \mu \mathrm{g} / \mathrm{ml}$,

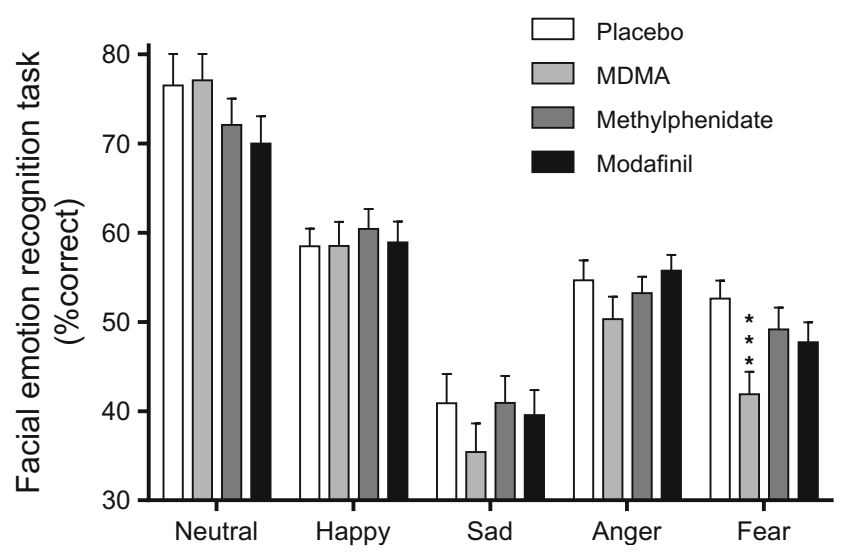

Fig. 5 On the Facial Emotion Recognition Task, MDMA significantly impaired the recognition of fearful faces compared with placebo. Methylphenidate and modafinil did not significantly alter emotion recognition. The data are expressed as the mean \pm SEM in 22 subjects respectively. The $T_{\max }$ values were $3.2 \pm 0.3$ and $3.3 \pm 0.3 \mathrm{~h}$, respectively.

\section{Adverse effects}

On the List of Complaints, MDMA, methylphenidate, and modafinil produced significant and comparable acute adverse effects (up to $6 \mathrm{~h}$ ) compared with placebo (Supplementary Table S1). The most frequent acute complaints were lack of appetite, dry mouth, and headache. Only modafinil produced significant adverse effects that lasted up to $24 \mathrm{~h}$ (mostly insomnia, headache, and lack or appetite). There were no severe adverse effects.

\section{Discussion}

The main finding of the present study was that oral administration of MDMA produced acute subjective, emotional, sensual/ sexual, and endocrine effects that were clearly distinct from those of the stimulant drugs methylphenidate and modafinil at oral doses that produced comparable sympathomimetic stimulant effects. The acute effects of MDMA (Dumont et al. 2009; Farre et al. 2004; Hysek et al. 2011; Kirkpatrick et al. 2014b; Liechti et al. 2001; Vollenweider et al. 1998), methylphenidate (Hysek et al. 2014b; Schmid et al. 2015b; Schmid et al. 2014), and modafinil (Jasinski 2000; Rush et al. 2002; Turner et al. 2003; Wong et al. 1999) have been previously described in healthy subjects. The present study further compared their acute responses within the same study and within the same 
subjects, thus providing direct and valid comparisons. The use of four drug conditions in the within-subject study eliminated any between-subject or between-study differences in comparisons of drug characteristics, and all drugs were administered blind in both active and passive control conditions. The primary research question was whether MDMA is simply a stimulant or whether it has unique namely prosocial and empathogenic effects that are distinct from other stimulants (Bershad et al. 2016). The present study clearly indicated that MDMA has a different effect profile than the stimulant methylphenidate at the doses used, supporting previous, albeit less rigorous, study findings (Bershad et al. 2016; Hysek et al. 2014b; Schmid et al. 2015b; Schmid et al. 2014). Specifically, MDMA increased well-being, good drug effects, drug liking, happiness, trust, feelings of closeness to others, and wanting to be with others, and reduced state anxiety compared with methylphenidate and modafinil at the doses used. The distinct mood effects of MDMA were congruent with its effects on the FERT, including reductions of fear recognition and more misclassifications of emotions as happy. MDMA, but not methylphenidate, has previously been shown to reduce fear recognition on the FERT (Bedi et al. 2010; Hysek et al. 2014b; Kirkpatrick et al. 2014b; Schmid et al. 2014). Additionally, MDMA, but not methylphenidate or modafinil, strongly increased endocrine markers of acutely increased serotonergic activity, including cortisol and prolactin (Seifritz et al. 1996; Sommers et al. 1994; Strajhar et al. 2016). MDMA, but not methylphenidate or modafinil, also markedly increased pupil size at rest and after light stimulation, which is consistent with a previous study (Hysek and Liechti 2012) and other serotonergic substances (Schmid et al. 2015a). On the ARCI, methylphenidate and modafinil produced significantly fewer sedating effects than MDMA, which is consistent with their greater stimulant-type properties.

Pharmacologically, MDMA (Hysek et al. 2012c; White et al. 1996), methylphenidate (Han and Gu 2006; Rothman et al. 2001; Schmeichel and Berridge 2013), and modafinil (Madras et al. 2006; Rowley et al. 2014) all stimulate the noradrenergic system and consistently produced overall similar cardiostimulant effects in the present study. Additionally, MDMA releases serotonin (Hysek et al. 2012c; White et al. 1996) and oxytocin (Dumont et al. 2009; Hysek et al. 2012b; Hysek et al. 2014a; Kuypers et al. 2017; Schmid et al. 2014; Thompson et al. 2007), whereas methylphenidate and modafinil act as dopamine uptake inhibitors (Madras et al. 2006; Rothman et al. 2001). Consistent with the different pharmacological profiles of these substances, MDMA exerted distinct subjective effects across all of our rating scales (VASs, AMRS, ARCI, 5D-ASC, and SADI) compared with methylphenidate and modafinil at the doses used. Consistent with the present study, we previously reported greater well-being, happiness, extroversion, and feelings of closeness after $125 \mathrm{mg}$ MDMA administration compared with $60 \mathrm{mg}$ methylphenidate (Hysek et al. 2014b) and after $75 \mathrm{mg}$ MDMA administration compared with $40 \mathrm{mg}$ methylphenidate (Schmid et al. 2014).

In the present study, MDMA increased circulating concentrations of cortisol, prolactin, and oxytocin as previously shown for different doses of MDMA (Harris et al. 2002; Hysek et al. 2012b; Hysek et al. 2014a; Joyce et al. 1986; Kirkpatrick et al. 2014b; Mas et al. 1999; Schmid et al. 2014; Seibert et al. 2014). MDMA did not alter plasma concentrations of vasopressin, which is consistent with previous studies that reported no change in the concentrations of the vasopressin precursor copeptin (Hysek et al. 2014a; Schmid et al. 2014). In contrast, higher levels of vasopressin following MDMA administration were reported in some earlier studies (Forsling et al. 2001; Henry et al. 1998), and one study reported higher concentrations of the vasopressin precursor copeptin in females (Simmler et al. 2011). Methylphenidate only slightly increased plasma concentrations of cortisol in the present study, which is consistent with no or weak effects of methylphenidate that were reported in other studies (Hysek et al. 2014b; Joyce et al. 1986; Schmid et al. 2014; Seibert et al. 2014). Modafinil had no effects on plasma cortisol, prolactin, oxytocin, or vasopressin concentrations, which is consistent with previous reports for cortisol (Brun et al. 1998). Altogether, the main endocrine finding of the present study was that only MDMA produced marked increases in cortisol, prolactin, and oxytocin concentrations, which is consistent with similar effects of other serotonergic substances (Schmid et al. 2015a; Seibert et al. 2014; Seifritz et al. 1996; Strajhar et al. 2016).

The present study used a relatively high dose of modafinil $(600 \mathrm{mg})$, which did not produce significant or relevant subjective effects despite pronounced cardiostimulant and adverse effects, including insomnia, that lasted up to $24 \mathrm{~h}$. Similarly, modafinil produced no subjective mood effects at doses of 100-400 mg (Franke et al. 2017; Muller et al. 2013; Scoriels et al. 2011; Turner et al. 2003). However, modafinil increased misclassifications of emotions as angry on the FERT. Higher subjective anxiety and aggression were reported after administration of 100 and $200 \mathrm{mg}$ modafinil in young (Randall et al. 2003) but not middle-aged (Randall et al. 2004) healthy volunteers. Modafinil improved the recognition of sad faces in psychotic patients (Scoriels et al. 2011), a finding that was not replicated in the present study in healthy subjects. Consistent with its use as a promoter of wakefulness, 100 and $200 \mathrm{mg}$ modafinil increased alertness in healthy subjects in another study (Turner et al. 2003). Compared with the present study that used a relatively high dose of $600 \mathrm{mg}$, modafinil had moderate hemodynamic effects at doses of 100-200 mg (Turner et al. 2004; Turner et al. 2003).

In contrast to modafinil, methylphenidate produced significant subjective good drug effects and drug liking and produced moderate increases in feeling open and close to others compared with placebo. In contrast to the effects of MDMA, methylphenidate increased STAI state anxiety and tended to increase subjective concentration, which is consistent with its 
stimulant properties and use as a cognitive enhancer (Liakoni et al. 2015; Maier et al. 2015; Maier et al. 2013).

In the present study and at the doses used, MDMA, but not methylphenidate or modafinil, increased ratings of sexual arousal and desire on the SADI. This finding was unexpected because dopaminergic stimulants, including cocaine, methamphetamine, and methylphenidate, have been previously shown to increase sexual desire and arousal (Frohmader et al. 2010; Rawson et al. 2002; Schmid et al. 2015b; Semple et al. 2002). Interestingly, intravenous (Volkow et al. 2007) but not oral (Volkow et al. 2007) administration of methylphenidate enhanced self-reported sexual desire, which is consistent with the lack of sexual stimulant effects of oral methylphenidate that was observed in the present study. We previously reported that methylphenidate, but not MDMA, increased sexual arousal that was elicited by explicit visual sexual stimuli (Schmid et al. 2015b). The SADI is very different from the test that was used in the previous study. No stimuli were presented, and subjects simply rated the intensity of various sensations that are typically related to sexual stimulation but without a specific sexual context or related stimuli. MDMA increased many sensations that comprise the "Evaluative" and "Physiological" factors of the SADI, including ratings of enthusiastic, happy, sensual, pleasure, warm all over, and heart beats faster, in a potentially nonspecific sexually related manner. Although the subjects were instructed to make ratings on the SADI specifically with regard to sexual arousal and desire, their ratings may have been confounded by direct somatic and subjective drug effects of MDMA that are unrelated to sexual stimulation. Thus, one may argue that MDMA produced many physiological effects that also coincide with sexual arousal. Other studies reported increases in sexual arousal after methylphenidate but not MDMA administration (Frohmader et al. 2010; Schmid et al. 2015b; Volkow et al. 2007). MDMA users report inconsistent effects on sexual arousal and desire (McElrath 2005; Passie et al. 2005; Theall et al. 2006). MDMA appears to enhance pleasurable sensations, touch, and physical closeness rather than actual sexual engagement, and it reportedly impairs sexual performance (Frohmader et al. 2010; Passie et al. 2005; Theall et al. 2006; Zemishlany et al. 2001). Remaining unclear is whether MDMA produces actual sexual arousal or heightened motivation to engage in sexual activity.

The present study has limitations. We mainly used only one dose of each substance. It is difficult if not impossible to compare active substances if only one dose is used. Thus, the observed differences between drugs were seen at the doses used in this study but may not be present at different doses. However, dose-effect relationships show $E_{\max }$ curve characteristics (Hysek et al. 2012c) and we used single but relatively high doses of all drugs expected to result in subjective drug effects close to $E_{\max }$ based on previous studies (Hysek et al. 2012a; Hysek et al. 2012c). MDMA was used at an average dose of $1.9 \mathrm{mg} / \mathrm{kg}$ resulting in high mean peak plasma concentrations of $192 \mathrm{ng} / \mathrm{ml}$ clearly above the $\mathrm{EC}_{50}$ values of 44 and $93 \mathrm{ng} / \mathrm{ml}$ MDMA for the cardiostimulant and subjective effects, respectively (Hysek et al. 2012a; Hysek et al. 2012c). Thus, it can be assumed that near-maximal effects were reached at the MDMA dose used in the present study. Similarly, the single doses of methylphenidate and modafinil were high (sixfold the therapeutic starting doses for both substances), and plasma concentrations of methylphenidate and modafinil were twofold higher compared to those in another study using lower doses (Franke et al. 2017). Importantly, all of the drugs produced comparable overall sympathomimetic stimulation as reflected by the similar increase in the peak rate-pressure product and consistent with our attempt to match the doses based on previous data (Hysek et al. 2014b; Jasinski 2000) to produce similar cardiovascular effects. The distinct effects of MDMA and the other two stimulants were seen at the doses used in the present study. However, similarly distinct profiles were reported for MDMA and methylphenidate using identical and also lower doses of both substances and including also dose-response analyses (Hysek et al. 2014b; Schmid et al. 2014). The plasma concentration-time curves of all substances and metabolites measured in the present study were in the expected range based on pharmacokinetic data from other studies (de la Torre et al. 2000; Wong et al. 1998). The $C_{\max }$ was similar, but the mean $T_{\max }(3.2 \mathrm{~h})$ of methylphenidate was longer compared with our previous study ( $2.3 \mathrm{~h}$ ) (Hysek et al. 2014b). Importantly, $T_{\max }$ values were comparable for all substances used in the present study. Nevertheless, it should be acknowledged that comparisons across substances could be biased by differences in dose and pharmacokinetics.

Another issue relates to the use of many psychometric scales in the present study with the intention to more comprehensively and sensitively describe and compare the effects of the psychoactive substances. This may have increased the risk of change findings. However, the primary study hypothesis of greater socioemotional effects of MDMA compared to methylphenidate and modafinil at the doses used was confirmed. However, the differential effects of the substances on the STAI, ARCI, and SADI should be regarded as exploratory.

In conclusion, MDMA produced acute subjective, emotional, and endocrine effects that were distinct from those of methylphenidate and modafinil at the doses used, which is consistent with their different pharmacological profiles. Modafinil produced acute sympathomimetic stimulation that was comparable to methylphenidate and MDMA, but modafinil produced no emotional or subjective effects at the relatively high dose used.

Acknowledgements The authors acknowledge the assistance of Samuel Harder and Niklaus Denier in study management, Urs Duthaler and Anna Rickli in the measurement of drug plasma concentrations, and Michael Arends for text editing. 
Compliance with ethical standards The study was conducted in accordance with the Declaration of Helsinki and approved by the local ethics committee. All of the subjects provided written consent before participating in the study.

Conflict of interest The authors declare that they have no conflict of interest.

Funding This work was supported by the Swiss National Science Foundation (grant no. 320030_170249 to MEL and SB) and the University of Basel (to FM).

Open Access This article is distributed under the terms of the Creative Commons Attribution 4.0 International License (http:// creativecommons.org/licenses/by/4.0/), which permits unrestricted use, distribution, and reproduction in any medium, provided you give appropriate credit to the original author(s) and the source, provide a link to the Creative Commons license, and indicate if changes were made.

\section{References}

Bedi G, Hyman D, de Wit H (2010) Is ecstasy an "empathogen"? Effects of \pm 3 ,4-methylenedioxymethamphetamine on prosocial feelings and identification of emotional states in others. Biol Psychiatry 68: $1134-1140$

Bershad AK, Miller MA, Baggott MJ, de Wit H (2016) The effects of MDMA on socio-emotional processing: does MDMA differ from other stimulants? J Psychopharmacol 30:1248-1258

Bopp G, Bender W, Schütz CG (2005) Validierung der Deutschen Version des Addiction Research Center Inventory (ARCI). Suchtmedizin 7:152-153

Brun J, Chamba G, Khalfallah Y, Girard P, Boissy I, Bastuji H, Sassolas G, Claustrat B (1998) Effect of modafinil on plasma melatonin, cortisol and growth hormone rhythms, rectal temperature and performance in healthy subjects during a $36 \mathrm{~h}$ sleep deprivation. J Sleep Res 7:105-114

Brunt TM, Koeter MW, Niesink RJ, van den Brink W (2012) Linking the pharmacological content of ecstasy tablets to the subjective experiences of drug users. Psychopharmacology 220:751-762

de la Torre R, Farre M, Roset PN, Lopez CH, Mas M, Ortuno J, Menoyo E, Pizarro N, Segura J, Cami J (2000) Pharmacology of MDMA in humans. Ann N Y Acad Sci 914:225-237

Dittrich A (1998) The standardized psychometric assessment of altered states of consciousness (ASCs) in humans. Pharmacopsychiatry 31(Suppl 2):80-84

Dumont GJ, Verkes RJ (2006) A review of acute effects of 3,4methylenedioxymethamphetamine in healthy volunteers. J Psychopharmacol 20:176-187

Dumont GJ, Sweep FC, van der Steen R, Hermsen R, Donders AR, Touw DJ, van Gerven JM, Buitelaar JK, Verkes RJ (2009) Increased oxytocin concentrations and prosocial feelings in humans after ecstasy (3,4-methylenedioxymethamphetamine) administration. Soc Neurosci 4:359-366

Farre M, de la Torre R, Mathuna BO, Roset PN, Peiro AM, Torrens M, Ortuno J, Pujadas M, Cami J (2004) Repeated doses administration of MDMA in humans: pharmacological effects and pharmacokinetics. Psychopharmacology 173:364-375

Forsling M, Fallon JK, Kicman AT, Hutt AJ, Cowan DA, Henry JA (2001) Arginine vasopressin release in response to the administration of 3,4-methylenedioxymethamphetamine ("ecstasy"): is metabolism a contributory factor? J Pharm Pharmacol 53:1357-1363
Francis SM, Kirkpatrick MG, de Wit H, Jacob S (2016) Urinary and plasma oxytocin changes in response to MDMA or intranasal oxytocin administration. Psychoneuroendocrinology 74:92-100

Franke AG, Gransmark P, Agricola A, Schuhle K, Rommel T, Sebastian A, Ballo HE, Gorbulev S, Gerdes C, Frank B, Ruckes C, Tuscher O, Lieb K (2017) Methylphenidate, modafinil, and caffeine for cognitive enhancement in chess: a double-blind, randomised controlled trial. Eur Neuropsychopharmacol 27:248-260

Frohmader KS, Pitchers KK, Balfour ME, Coolen LM (2010) Mixing pleasures: review of the effects of drugs on sex behavior in humans and animal models. Horm Behav 58:149-162

Han DD, Gu HH (2006) Comparison of the monoamine transporters from human and mouse in their sensitivities to psychostimulant drugs. BMC Pharmacol 6:6

Hannestad J, Gallezot JD, Planeta-Wilson B, Lin SF, Williams WA, van Dyck CH, Malison RT, Carson RE, Ding YS (2010) Clinically relevant doses of methylphenidate significantly occupy norepinephrine transporters in humans in vivo. Biol Psychiatry 68:854-860

Harris DS, Baggott M, Mendelson JH, Mendelson JE, Jones RT (2002) Subjective and hormonal effects of 3,4methylenedioxymethamphetamine (MDMA) in humans. Psychopharmacology 162:396-405

Henry JA, Fallon JK, Kicman AT, Hutt AJ, Cowan DA, Forsling M (1998) Low-dose MDMA ("ecstasy”) induces vasopressin secretion. Lancet 351:1784

Hysek CM, Liechti ME (2012) Effects of MDMA alone and after pretreatement with reboxetine, duloxetine, clonidine, carvedilol, and doxazosin on pupillary light reflex. Psychopharmacology 224: 363-376

Hysek CM, Vollenweider FX, Liechti ME (2010) Effects of a betablocker on the cardiovascular response to MDMA (ecstasy). Emerg Med J 27:586-589

Hysek CM, Simmler LD, Ineichen M, Grouzmann E, Hoener MC, Brenneisen R, Huwyler J, Liechti ME (2011) The norepinephrine transporter inhibitor reboxetine reduces stimulant effects of MDMA ("ecstasy") in humans. Clin Pharmacol Ther 90:246-255

Hysek CM, Brugger R, Simmler LD, Bruggisser M, Donzelli M, Grouzmann E, Hoener MC, Liechti ME (2012a) Effects of the al$\mathrm{pha}_{2}$-adrenergic agonist clonidine on the pharmacodynamics and pharmacokinetics of 3,4-methylenedioxymethamphetamine in healthy volunteers. J Pharmacol Exp Ther 340:286-294

Hysek CM, Domes G, Liechti ME (2012b) MDMA enhances "mind reading" of positive emotions and impairs "mind reading" of negative emotions. Psychopharmacology 222:293-302

Hysek CM, Simmler LD, Nicola V, Vischer N, Donzelli M, Krähenbühl S, Grouzmann E, Hoener MC, Liechti ME (2012c) Duloxetine inhibits effects of MDMA ("ecstasy") in vitro and in humans in a randomized placebo-controlled laboratory study. PLoS One 7: e36476

Hysek CM, Schmid Y, Simmler LD, Domes G, Heinrichs M, Eisenegger C, Preller KH, Quednow BB, Liechti ME (2014a) MDMA enhances emotional empathy and prosocial behavior. Soc Cogn Affect Neurosci 9:1645-1652

Hysek CM, Simmler LD, Schillinger N, Meyer N, Schmid Y, Donzelli M, Grouzmann E, Liechti ME (2014b) Pharmacokinetic and pharmacodynamic effects of methylphenidate and MDMA administered alone and in combination. Int J Neuropsychopharmacol 17:371-381

Janke W, Debus G (1978) Die Eigenschaftswörterliste. Hogrefe, Göttingen

Jasinski DR (2000) An evaluation of the abuse potential of modafinil using methylphenidate as a reference. J Psychopharmacol 14:53-60

Joyce PR, Donald RA, Nicholls MG, Livesey JH, Abbott RM (1986) Endocrine and behavioral responses to methylphenidate in normal subjects. Biol Psychiatry 21:1015-1023

Kamilar-Britt P, Bedi G (2015) The prosocial effects of 3,4methylenedioxymethamphetamine (MDMA): controlled studies in 
humans and laboratory animals. Neurosci Biobehav Rev 57:433446

Kirkpatrick MG, Baggott MJ, Mendelson JE, Galloway GP, Liechti ME, Hysek CM, de Wit H (2014a) MDMA effects consistent across laboratories. Psychopharmacology 231:3899-3905

Kirkpatrick MG, Lee R, Wardle MC, Jacob S, de Wit H (2014b) Effects of MDMA and intranasal oxytocin on social and emotional processing. Neuropsychopharmacology 39:1654-1663

Kirkpatrick M, Delton AW, Robertson TE, de Wit H (2015) Prosocial effects of MDMA: a measure of generosity. J Psychopharmacol 29: 661-668

Korostenskaja M, Kicic D, Kahkonen S (2008) The effect of methylphenidate on auditory information processing in healthy volunteers: a combined EEG/MEG study. Psychopharmacology 197:475-486

Kuypers KPC, Dolder PC, Ramaekers JG, Liechti ME (2017) Multifaceted empathy of healthy volunteers after single doses of MDMA: a pooled sample of placebo-controlled studies. J Psychopharmacol 31:589-598

Liakoni E, Schaub MP, Maier LJ, Glauser GV, Liechti ME (2015) The use of prescription drugs, recreational drugs, and "soft enhancers" for cognitive enhancement among Swiss secondary school students. PLoS One 10:e141289

Liechti M (2015) Novel psychoactive substances (designer drugs): overview and pharmacology of modulators of monoamine signaling. Swiss Med Wkly 145:w14043

Liechti ME, Gamma A, Vollenweider FX (2001) Gender differences in the subjective effects of MDMA. Psychopharmacology 154:161168

Madras BK, Xie Z, Lin Z, Jassen A, Panas H, Lynch L, Johnson R, Livni E, Spencer TJ, Bonab AA, Miller GM, Fischman AJ (2006) Modafinil occupies dopamine and norepinephrine transporters in vivo and modulates the transporters and trace amine activity in vitro. J Pharmacol Exp Ther 319:561-569

Maier LJ, Liechti ME, Herzig F, Schaub MP (2013) To dope or not to dope: neuroenhancement with prescription drugs and drugs of abuse among Swiss university students. PLoS One 8:e77967

Maier LJ, Liakoni E, Schildmann J, Schaub MP, Liechti ME (2015) Swiss university students' attitudes toward pharmacological cognitive enhancement. PLoS One 10:e144402

Makris AP, Rush CR, Frederich RC, Taylor AC, Kelly TH (2007) Behavioral and subjective effects of $\mathrm{d}$-amphetamine and modafinil in healthy adults. Exp Clin Psychopharmacol 15:123-133

Martin WR, Sloan JW, Sapira JD, Jasinski DR (1971) Physiologic, subjective, and behavioral effects of amphetamine, methamphetamine, ephedrine, phenmetrazine, and methylphenidate in man. Clin Pharmacol Ther 12:245-258

Mas M, Farre M, de la Torre R, Roset PN, Ortuno J, Segura J, Cami J (1999) Cardiovascular and neuroendocrine effects and pharmacokinetics of 3, 4-methylenedioxymethamphetamine in humans. J Pharmacol Exp Ther 290:136-145

McElrath K (2005) MDMA and sexual behavior: ecstasy users' perceptions about sexuality and sexual risk. Subst Use Misuse 40:14611477

Mithoefer MC, Wagner MT, Mithoefer AT, Jerome I, Doblin R (2010) The safety and efficacy of $\pm 3,4$-methylenedioxymethamphetamineassisted psychotherapy in subjects with chronic, treatment-resistant posttraumatic stress disorder: the first randomized controlled pilot study. J Psychopharmacol 25:439-452

Muller U, Rowe JB, Rittman T, Lewis C, Robbins TW, Sahakian BJ (2013) Effects of modafinil on non-verbal cognition, task enjoyment and creative thinking in healthy volunteers. Neuropharmacology 64 : 490-495

Neumann ID, Maloumby R, Beiderbeck DI, Lukas M, Landgraf R (2013) Increased brain and plasma oxytocin after nasal and peripheral administration in rats and mice. Psychoneuroendocrinology 38:19851993
Oehen P, Traber R, Widmer V, Schnyder U (2013) A randomized, controlled pilot study of MDMA ( $\pm 3,4$-methylenedioxymethamphetamine)assisted psychotherapy for treatment of resistant, chronic posttraumatic stress disorder (PTSD). J Psychopharmacol 27:40-52

Parrott AC, Gibbs A, Scholey AB, King R, Owens K, Swann P, Ogden E, Stough C (2011) MDMA and methamphetamine: some paradoxical negative and positive mood changes in an acute dose laboratory study. Psychopharmacology 215:527-536

Passie T, Hartmann U, Schneider U, Emrich HM, Kruger TH (2005) Ecstasy (MDMA) mimics the post-orgasmic state: impairment of sexual drive and function during acute MDMA-effects may be due to increased prolactin secretion. Med Hypotheses 64:899-903

Persson TJ, Ryder AG, Pfaus JG (2016) Comparing subjective ratings of sexual arousal and desire in partnered sexual activities from women of different sexual orientations. Arch Sex Behav 45:1391-1402

Qu WM, Huang ZL, Xu XH, Matsumoto N, Urade Y (2008) Dopaminergic D1 and D2 receptors are essential for the arousal effect of modafinil. J Neurosci 28:8462-8469

Randall DC, Shneerson JM, Plaha KK, File SE (2003) Modafinil affects mood, but not cognitive function, in healthy young volunteers. Hum Psychopharmacol 18:163-173

Randall DC, Fleck NL, Shneerson JM, File SE (2004) The cognitiveenhancing properties of modafinil are limited in non-sleepdeprived middle-aged volunteers. Pharmacol Biochem Behav 77: 547-555

Rawson RA, Washton A, Domier CP, Reiber C (2002) Drugs and sexual effects: role of drug type and gender. J Subst Abus Treat 22:103-108

Repantis D, Schlattmann P, Laisney O, Heuser I (2010) Modafinil and methylphenidate for neuroenhancement in healthy individuals: a systematic review. Pharmacol Res 62:187-206

Rothman RB, Baumann MH, Dersch CM, Romero DV, Rice KC, Carroll FI, Partilla JS (2001) Amphetamine-type central nervous system stimulants release norepinephrine more potently than they release dopamine and serotonin. Synapse 39:32-41

Rowley HL, Kulkarni RS, Gosden J, Brammer RJ, Hackett D, Heal DJ (2014) Differences in the neurochemical and behavioural profiles of lisdexamfetamine methylphenidate and modafinil revealed by simultaneous dual-probe microdialysis and locomotor activity measurements in freely-moving rats. J Psychopharmacol 28:254-269

Rush CR, Kelly TH, Hays LR, Baker RW, Wooten AF (2002) Acute behavioral and physiological effects of modafinil in drug abusers. Behav Pharmacol 13:105-115

Schmeichel BE, Berridge CW (2013) Neurocircuitry underlying the preferential sensitivity of prefrontal catecholamines to low-dose psychostimulants. Neuropsychopharmacology 38:1079-1084

Schmid Y, Hysek CM, Simmler LD, Crockett MJ, Quednow BB, Liechti ME (2014) Differential effects of MDMA and methylphenidate on social cognition. J Psychopharmacol 28:847-856

Schmid Y, Enzler F, Gasser P, Grouzmann E, Preller KH, Vollenweider FX, Brenneisen R, Muller F, Borgwardt S, Liechti ME (2015a) Acute effects of lysergic acid diethylamide in healthy subjects. Biol Psychiatry 78:544-553

Schmid Y, Hysek CM, Preller KH, Bosch OG, Bilderbeck AC, Rogers RD, Quednow BB, Liechti ME (2015b) Effects of methylphenidate and MDMA on appraisal of erotic stimuli and intimate relationships. Eur Neuropsychopharmacol 25:17-25

Scoriels L, Barnett JH, Murray GK, Cherukuru S, Fielding M, Cheng F, Lennox BR, Sahakian BJ, Jones PB (2011) Effects of modafinil on emotional processing in first episode psychosis. Biol Psychiatry 69: 457-464

Seibert J, Hysek CM, Penno CA, Schmid Y, Kratschmar DV, Liechti ME, Odermatt A (2014) Acute effects of 3,4methylenedioxymethamphetamine and methylphenidate on circulating steroid levels in healthy subjects. Neuroendocrinology 100:17-25

Seifritz E, Baumann P, Muller MJ, Annen O, Amey M, Hemmeter U, Hatzinger M, Chardon F, Holsboer-Trachsler E (1996) 
Neuroendocrine effects of a 20-mg citalopram infusion in healthy males: a placebo-controlled evaluation of citalopram as 5-HT function probe. Neuropsychopharmacology 14:253-263

Semple SJ, Patterson TL, Grant I (2002) Motivations associated with methamphetamine use among HIV+ men who have sex with men. J Subst Abus Treat 22:149-156

Simmler LD, Hysek CM, Liechti ME (2011) Sex differences in the effects of MDMA (ecstasy) on plasma copeptin in healthy subjects. J Clin Endocrinol Metab 96:2844-2850

Simmler L, Buser T, Donzelli M, Schramm Y, Dieu LH, Huwyler J, Chaboz S, Hoener M, Liechti ME (2013) Pharmacological characterization of designer cathinones in vitro. Br J Pharmacol 168:458470

Simmler LD, Rickli A, Schramm Y, Hoener MC, Liechti ME (2014) Pharmacological profiles of aminoindanes, piperazines, and pipradrol derivatives. Biochem Pharmacol 88:237-244

Sommers DK, van Wyk M, Snyman JR (1994) Dexfenfluramine-induced prolactin release as an index of central synaptosomal 5hydroxytryptamine during treatment with fluoxetine. Eur J Clin Pharmacol 46:441-444

Spielberger CD, Gorsuch RC, Lusheme RE (1970) Manual for the Stait Trait Anxiety Inventory. Consulting Psychologists Press, Palo Alto

Strajhar P, Schmid Y, Liakoni E, Dolder PC, Rentsch KM, Kratschmar DV, Odermatt A, Liechti ME (2016) Acute effects of lysergic acid diethylamide on circulating steroid levels in healthy subjects. J Neuroendocrinol 28:12374

Studerus E, Gamma A, Vollenweider FX (2010) Psychometric evaluation of the altered states of consciousness rating scale (OAV). PLoS One $5: \mathrm{e} 12412$

Tancer M, Johanson CE (2003) Reinforcing, subjective, and physiological effects of MDMA in humans: a comparison with d-amphetamine and mCPP. Drug Alcohol Depend 72:33-44

Theall KP, Elifson KW, Sterk CE (2006) Sex, touch, and HIV risk among ecstasy users. AIDS Behav 10:169-178

Thompson MR, Callaghan PD, Hunt GE, Cornish JL, McGregor IS (2007) A role for oxytocin and 5- $\mathrm{HT}_{1 \mathrm{~A}}$ receptors in the prosocial effects of 3,4 methylenedioxymethamphetamine ("ecstasy"). Neuroscience 146:509-514

Toledano R, Pfaus J (2006) The Sexual Arousal and Desire Inventory (SADI): a multidimensional scale to assess subjective sexual arousal and desire. J Sex Med 3:853-877
Turner DC, Robbins TW, Clark L, Aron AR, Dowson J, Sahakian BJ (2003) Cognitive enhancing effects of modafinil in healthy volunteers. Psychopharmacology 165:260-269

Turner DC, Clark L, Dowson J, Robbins TW, Sahakian BJ (2004) Modafinil improves cognition and response inhibition in adult attention-deficit/hyperactivity disorder. Biol Psychiatry 55:1031-1040

Vizeli P, Liechti ME (2017) Safety pharmacology of acute MDMA administration in healthy subjects. J Psychopharmacol 31:576-588

Volkow ND, Wang GJ, Fowler JS, Telang F, Jayne M, Wong C (2007) Stimulant-induced enhanced sexual desire as a potential contributing factor in HIV transmission. Am J Psychiatry 164:157-160

Vollenweider FX, Gamma A, Liechti ME, Huber T (1998) Psychological and cardiovascular effects and short-term sequelae of MDMA ("ecstasy") in MDMA-naive healthy volunteers. Neuropsychopharmacology 19:241-251

White SR, Obradovic T, Imel KM, Wheaton MJ (1996) The effects of methylenedioxymethamphetamine (MDMA, "ecstasy") on monoaminergic neurotransmission in the central nervous system. Prog Neurobiol 49:455-479

White TL, Justice AJ, de Wit H (2002) Differential subjective effects of D-amphetamine by gender, hormone levels and menstrual cycle phase. Pharmacol Biochem Behav 73:729-741

Wong YN, King SP, Laughton WB, McCormick GC, Grebow PE (1998) Single-dose pharmacokinetics of modafinil and methylphenidate given alone or in combination in healthy male volunteers. J Clin Pharmacol 38:276-282

Wong YN, Simcoe D, Hartman LN, Laughton WB, King SP, McCormick GC, Grebow PE (1999) A double-blind, placebo-controlled, ascending-dose evaluation of the pharmacokinetics and tolerability of modafinil tablets in healthy male volunteers. J Clin Pharmacol 39: $30-40$

Zemishlany Z, Aizenberg D, Weizman A (2001) Subjective effects of MDMA ('ecstasy') on human sexual function. Eur Psychiatry 16: $127-130$

Zerssen DV (1976) Die Beschwerden-Liste. Münchener Informationssystem. Psychis, München

Zolkowska D, Jain R, Rothman RB, Partilla JS, Roth BL, Setola V, Prisinzano TE, Baumann MH (2009) Evidence for the involvement of dopamine transporters in behavioral stimulant effects of modafinil. J Pharmacol Exp Ther 329:738-746 